\title{
The discovery of magnetotactic/magnetosensitive bacteria
}

\author{
Richard B. FRANKEL \\ Department of Physics, California Polytechnic State University, San Luis Obispo, CA 93407 USA
}

Keywords: magnetotaxis; magnetosensitivity; bacteria; discovery

Magnetotactic bacteria orient and migrate along magnetic field lines in aquatic habitats. The first paper on this phenomenon was written by Richard P. Blakemore (Blakemore, 1975; 1982). In that paper, Blakemore described bacteria collected from a pond in Woods Hole, Massachusetts that migrated persistently northward in the geomagnetic field. He named the behavior "magnetotaxis." He proposed that northward migration along geomagnetic field lines in the northern hemisphere would cause the bacteria to move downward toward the micro-aerobic or anaerobic zone of the habitat. $\mathrm{He}$ also used electron microscopy to show that the bacteria contained nano-scale, iron rich, crystals that he surmised were responsible for magnetotaxis. Blakemore's papers initiated a vigorous, international, study of magnetotactic bacteria that continues to this day (Schueler, 2007); it has been cited over 650 times in the scientific literature.

Recently, two unpublished manuscripts dated 1963 have been found that report on "magnetosensitivity" in aquatic bacteria. The manuscripts, entitled "On a unique behavior of fresh water bacteria" (Bellini, 1963a) and "Further studies on magnetosensitive bacteria" (Bellini, 1963b), were written by Salvatore Bellini, a medical doctor who was working in the Institute of Microbiology at the University of Pavia, Italy. According to Bellini (private communication), he serendipitously discovered the magnetosensitive bacteria in 1958 while examining water samples from sources around Pavia for pathogens. He was encouraged by the institute director (Prof. L. Bianchi) to continue research on the magnetosensitive bacteria; the research program concluded in 1963 with the writing of the two manuscripts. He intended to submit the manuscripts for publication in a scientific journal, but did not receive the necessary permission from a panel of senior faculty who reviewed all research manuscripts from the University before submission. The institute director then encouraged him to send copies of the manuscripts to some universities and research institutions in Italy.

Copies of the two manuscripts came into my possession in 2007 via Dr. Henrique Lins de Barros (Brazil) and Prof. Dennis A. Bazylinski (USA). I had the manuscripts translated into English from the original Italian by Ms. Elena Scanu, a native speaker of Italian. I then edited the translations for scientific clarity. To the best of my ability I tried keep the translations as true as possible to Bellini's original language and meaning. The translations were subsequently sent to Bellini for his review and concurrence.

The first manuscript, Bellini 1963a, describes observation of various morphotypes of bacteria in water samples that swam persistently northward and collected at the North edge of water drops on microscope slides. He named this behavior "magnetosensitivity". Among other things, he observed: a) local magnetic fields produced by bar magnets or small electromagnets could overcome the geomagnetic field and determine the swimming direction of the bacteria in the water drops; b) dead cells oriented in the magnetic field but did not migrate; c) magnetosensitivity was lost in cells enriched in demineralized water, but was restored by addition of soluble iron. On the basis of these observations, he hypothesized that: a) the bacteria contain an internal, biomagnetic dipole; b) the magnetic dipole caused cells to migrate downward in the northern hemisphere toward the less oxygenated bottom sediments; c) magnetosensitive bacteria in the southern hemisphere should swim toward the South magnetic pole; d) the biomagnetic dipole was fashioned from iron compounds. In the second 
manuscript, Bellini 1963b, he described his materials and experimental methods for studying magnetosensitivity and for separating magnetosensitive cells from other cells. He also described experiments showing how alteration of the ambient gas (air to pure nitrogen or pure oxygen) changed the behavior of the cells.

The experimental observations presented by Bellini in the two manuscripts correspond very well with the observations of Blakemore and others. Thus it is certain to me that magnetosensitivity and magnetotaxis are the same behavior. Blakemore had the advantage of electron microscopy by which he discovered the magnetosomes; this instrument was apparently unavailable to Bellini. Nevertheless, it is clear that Bellini's manuscripts document a valid scientific discovery, and support his claim to the discovery of magnetosensitive/magnetotactic bacteria.

On the other hand, Bellini's discovery was not published in a peer-reviewed scientific journal. While the manuscripts were sent to a number of institutions in Italy, they were not well known. As far as I know, they were not cited in any subsequent work, nor were some prominent microbiologists, including an Italian (Salvatore Luria), aware of the Bellini manuscripts even though they were very interested in Blakemore's paper. From this I conclude that Bellini's work was unknown to most research scientists, including Blakemore, at the time Blakemore's 1975 paper was published. Therefore, we can say that all the subsequent research on magnetotactic bacteria derives from Blakemore's publication. So it may be fair to say that whereas Bellini was the first discoverer of magnetosensitivity/magnetotaxis, his discovery was effectively lost until Blakemore rediscovered the phenomenon 12 years later. This is why the name "magnetotactic bacteria" is widely used, whereas "magnetosensitive bacteria" is not used.

Nevertheless, Bellini did make a valid, first discovery and prescient hypotheses that were later verified. I believe he deserves to be acknowledged for this. I also believe that Blakemore must continue to be acknowledged for the discovery that led to the development of a whole field of scientific study. Therefore I propose that both discoveries be cited in future publications concerning magnetotactic bacteria. For this reason the English translations of the Bellini manuscripts have been submitted for publication in this issue of the Chinese Journal of Oceanography and Limnology, with S. Bellini as author. The manuscripts in the original Italian can be found on my website: http://www.calpoly.edu/ $\sim$ rfrankel/mtbother.html.

I thank Ms. E. Scanu for translation, Dr. H. Lins de Barros and Prof. D. A. Bazylinski for discussion, and Prof. L. F. Wu for help in publication. I also thank Dr. $\mathrm{S}$. Bellini for information concerning his discovery.

\section{References}

Bellini, S., 1963a. Su di un particolare comportamento di batteri d'acqua dolce (On a unique behavior of freshwater bacteria). Institute of Microbiology, University of Pavia, Italy.

Bellini, S., 1963b. Ulteriori studi sui "batteri magnetosensibili" (Further studies on magnetosensitive bacteria). Institute of Microbiology, University of Pavia, Italy.

Blakemore, R. P., 1975. Magnetotactic bacteria. Science 190: 377-379.

Blakemore, R. P., 1982. Magnetotactic bacteria. Annu. Rev. Microbiol. 36: 217-238.

Schueler, D., (editor), 2007. Magnetoreception and Magnetosomes in Bacteria. Springer, Heidelberg, Germany, 319p. 